\title{
Determination of moisture content in lyophilized mannitol through intact glass vials using NIR micro-spectrometers
}

\author{
Cristian Rodrigo Muzzio ${ }^{1,2, *}$, Nicolás Gabriel Dini², Laura Daniela Simionato
}

\author{
${ }^{1}$ Department of Chemistry, Faculty of Engineering, University of Buenos Aires, Buenos Aires, Argentina, ${ }^{2}$ Research and \\ Development Department, Hitec S.R.L., Buenos Aires, Argentina, ${ }^{3}$ Pharmaceutical Technologies Department, Quality Control \\ Laboratory, Faculty of Pharmacy and Biochemistry, University of Buenos Aires, Buenos Aires, Argentina
}

\begin{abstract}
Determination of moisture content in lyophilized solids is fundamental to predict quality and stability of freeze-dried products, but conventional methods are time-consuming, invasive and destructive. The aim of this study was to develop and optimize a fast, inexpensive, noninvasive and nondestructive method for determination of moisture content in lyophilized mannitol, based on an NIR micro-spectrometer instead of a conventional NIR spectrometer. Measurements of lyophilized mannitol were performed through the bottom of rotating glass vials by means of a reflectance probe. The root mean standard error of prediction (RMSEP) and the correlation coefficient $\left(\mathrm{R}_{\text {pred }}^{2}\right)$, yielded by the pre-treatments and calibration method proposed, was $0.233 \%(\mathrm{w} / \mathrm{w})$ and 0.994 , respectively.
\end{abstract}

Uniterms: Near-infrared spectroscopy. Lyophilization. Multivariate analysis. Moisture content. Mannitol. Micro-spectrometer.

\begin{abstract}
A determinação do conteúdo de umidade em sólidos liofilizados é fundamental para se prever a qualidade e a estabilidade de produtos liofilizados, mas os métodos convencionais consomem muito tempo, são invasivos e destrutivos. O objetivo desse estudo foi desenvolver e otimizar um método rápido, econômico, não invasivo e não destrutivo para a determinação do conteúdo de umidade em manitol liofilizado, com base em microespectrômetro de infravermelho próximo ao invés de um espectrômetro de infravermelho próximo convencional. As medidas de manitol liofilizado foram realizadas através do fundo de recipiente de vidro em rotação por meio de sonda de reflectância. A raíz do erro médio padrão de predição (RMSEP) e o coeficiente de correlação $\left(\mathrm{R}_{\text {pred }}^{2}\right.$ ) obtidos pelo prétratamento e pelo método de calibração proposto foram, respectivamente, $0,233 \%(\mathrm{p} / \mathrm{p})$ e 0,994 .
\end{abstract}

Uniterms: Espectroscopia de infravermelho próximo. Liofilização. Análise multivariada. Análise de unidade. Manitol. Microespectrômetro.

\section{INTRODUCTION}

Lyophilization (freeze-drying) is a process performed to preserve a wide range of products which are unstable in the presence of water (Roggo et al., 2007). This process consists of three stages: freezing, primary drying and secondary drying. In the first stage, the product is frozen to low temperatures, usually between $-40^{\circ} \mathrm{C}$ and $-80^{\circ} \mathrm{C}$, for approximately 10 hours. Then, in the primary drying stage, the pressure in the drying chamber is reduced

\footnotetext{
*Correspondence: C. R. Muzzio. Departamento de Química, Facultad de Ingeniería, Universidad de Buenos Aires, Paseo Colón 850, (C1063ACV) - Buenos Aires - Argentina. E-mail: cmuzzio@fi.uba.ar
}

and enough heat is supplied to promote the sublimation of the water contained in the product. Finally, in the secondary drying stage, the temperature is raised and, sometimes, the pressure is reduced again.

As several studies show (Xie et al., 2008; Cannon, Trappler, 2000), precise control of the process and the use of substances known as lyoprotectants, are critical to preserve the integrity of the product and to ensure its stability. Due to its properties as a bulking agent and lyoprotectant, mannitol is commonly used as an excipient in lyophilized pharmaceutical products. Nevertheless, mannitol exists in various different forms, which depend on the processing conditions to be controlled, and has different properties that significantly affect the quality and stability of the pro- 
ducts that contain this excipient (Botez et al., 2003; Cao et al., 2006; Derbyshire et al., 2002). For example, mannitol hydrate is unstable and can release hydrate water during storage under ambient conditions, which can negatively affect the stability of the product (Cao et al., 2006). At higher moisture contents, Derbyshire et al. (Derbyshire et al., 2002) used different techniques to understand the properties of water in mannitol and presented evidence of two transitions at water contents of $c a .10 \%(\mathrm{w} / \mathrm{w})$ and $25-30 \%(\mathrm{w} / \mathrm{w})$, that indicate the existence of water with significantly different behavior. Hence, determining the amount and characteristics of water in mannitol is fundamental to predict the quality and stability of products that include this excipient.

Determination of moisture content in freeze-dried solids is typically done by Karl Fischer (KF) titration, thermogravimetry (TG) or gas chromatography (GC) (Roggo et al., 2007; Blanco et al., 1997; Zhou et al., 2003). Nevertheless, these methods are all time-consuming, invasive and destructive. Moreover, the sample to be analyzed may suffer contamination if the measurement is not carried out under appropriate conditions (Zhou et al., 2003; Kamat et al., 1989; Zheng et al., 2008). An ideal method should perform fast, non-invasive and non-destructive measurements with minimal or no sample preparation. These characteristics ensure that an entire batch can be thoroughly examined without modifying the content of vials. Over the last twenty years, several reports have been published concerning the determination of moisture content of lyophilized products by scanning through the bottom of vials (Kamat et al., 1989; Zheng et al., 2008; Derksen et al., 1998; Stokvold et al., 2002). Nonetheless, these studies have focused on development of models for accurate and precise at-line determinations by means of conventional spectrometers.

The present research was focused on measuring the total amount of water in lyophilized mannitol through intact glass vials with a reflectance probe and an NIR micro-spectrometer. Although conventional spectrometers have better resolution than micro-spectrometers, micro-spectrometers are relatively inexpensive and could be straightforwardly adapted to at-line and in-line measurements in production environments within the PAT (Process Analytical Technology) framework (FDA, 2004). The use of micro-spectrometers to determine the moisture content of lyophilized mannitol is, however, a challenging task owing to the combination of the inferior resolution of micro-spectrometers and the low signal intensity of mannitol with very low water content.

Different pre-treatment methods and calibration models were analyzed, and the best performance was achieved by means of the following combination: 4-point binomial smoothing, Standard Normal Variate (SNV) and Partial least-squares (PLS-1). The results indicate that fast, non-invasive, and non-destructive determinations of moisture content by means of micro-spectrometers along with the techniques and adjustments proposed in this study are possible.

\section{EXPERIMENTAL}

\section{Karl Fischer Titration}

Samples of lyophilized mannitol were supplied by Laboratorios IMA and most of these were analyzed for moisture content using a Titralab TIM-550 titrator (Radiometer Analytical SAS). The few remaining samples were analyzed using a G500 titrator (Groc Instruments). Results are given in the Karl Fischer Section.

\section{NIR Measurement}

NIR measurements were performed using a diffraction grating spectrometer (AvaSpec-NIR256-2.2, Avantes Inc.) with a 256-pixel InGaAs detector. Samples were measured through the bottom of the sealed glass vial. Each spectrum was the average of 295 spectra, collected over the $1100-2200 \mathrm{~nm}$ region, by continuously rotating the vial in such a way that the points of the vial where the probe respectively started and finished the measurement of each average spectrum were approximately coincident. A diagram of the set-up is shown in Figure 1. As recently proposed by Zheng et al. (Zheng et al., 2008), the rotator strongly improved the determinations in terms of repeatability. Also, the average spectrum obtained through this approach significantly reduced the effects related to physical differences among vials and differences in the base of the same vial.

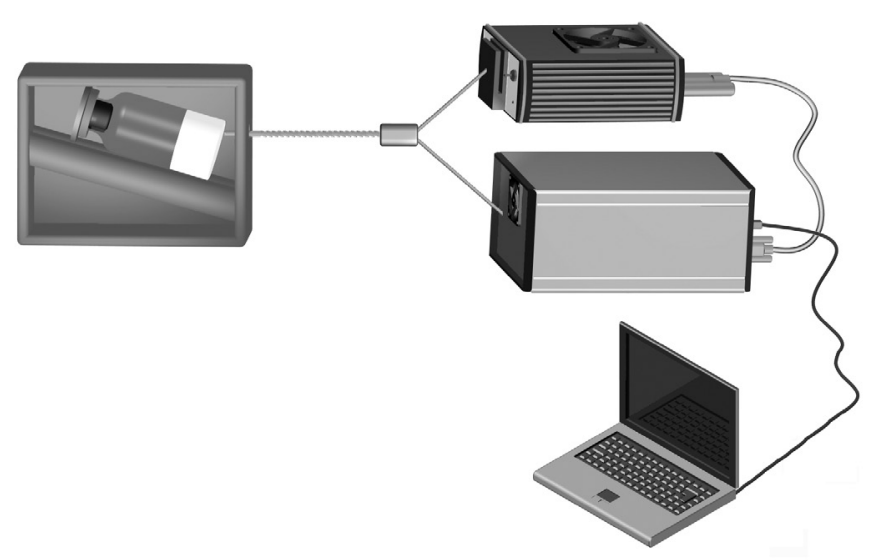

FIGURE 1 - Schematic illustration of system setup. 
In addition, the probe was inclined at a suitable angle in order to avoid direct reflections from the bottom of the vial. The analysis to obtain the best angle and the corresponding results are depicted in the Direct Reflections Section.

\section{Samples}

In this study, after lyophilization, the mannitol was immediately capped in clear glass vials in order to prevent the moisture content from changing. Subsequently, samples were divided into two groups: in the first group, 26 samples were analyzed without any further treatment after the drying process; in the second group, 27 sealed vials were injected with $4 \mathrm{mg}$ to $40 \mathrm{mg}$ of water. As a result, the vials, each containing approximately $350 \mathrm{mg}$ of mannitol, ranged in moisture content from $c a .0 .1 \%(\mathrm{w} / \mathrm{w})$ (no water added) up to approximately $8 \%(\mathrm{w} / \mathrm{w})$. From these samples, two sets were obtained: a calibration set comprising 14 untreated samples and 16 samples with added water, and a validation set comprising 12 untreated samples and 11 samples with added water.

In the last few years, many different methods to generate calibration and validation samples with a certain content of water have been described, e.g. by closing the vials at various time intervals (Kamat et al., 1989), by opening the freeze-drier at different times (Zheng et al., 2008) or by exposing the samples to environment humidity (Blanco et al., 1997; Stokvold et al., 2002; Brülls et al., 2007). Nevertheless, the method proposed in the present study is deemed to be comparatively easier to control and to produce more accurate and reproducible values, while the risk of contaminating the sample is minimized. The amount of injected water was accurately measured by means of a Rainin pipette (Rainin Instrument, LLC) model SL-20. After the injection and before the measurements, all the samples were stored for almost one month in order to ensure appropriate and homogeneous water distribution. After this period of time, most vials showed a variable volume reduction depending on the amount of injected water. Since NIR measurements in this study needed mannitol to be spread over the bottom of the vial, every freeze-dried cake that exhibited volume reduction was gently shaken. The changes in path length, bulk density and particle size related to the described process of sample generation are known sources of spectral variance (Berntsson et al., 1998). Thus, further analysis (described in the Spectrum Analysis Section) was carried out to determine the best pre-treatment method to avoid differences in the spectra after shaking.

Apart from the variation caused by changes in particle size and powder packing, several authors (Shenk et al., 2008; Büning-Pfaue, 2003) have reported spectral differences when NIR measurements are taken at different temperatures within relative narrow ranges (for example, between $15^{\circ} \mathrm{C}$ and $20^{\circ} \mathrm{C}$ ). The most common explanation for these spectral variations is based on changes in the hydrogen-bonded water structure. To improve the calibration model robustness to temperature fluctuations, spectra were acquired at four different temperatures $\left(18.1^{\circ} \mathrm{C}\right.$; $20.6{ }^{\circ} \mathrm{C} ; 22.2{ }^{\circ} \mathrm{C} ; 25.3{ }^{\circ} \mathrm{C}$ ) from every sample of the validation and calibration set. The analysis of the model robustness related to temperature influence is shown in the Direct Reflections Section. Finally, the calibration and validation sets consisted of 30 and 23 samples, respectively.

\section{Spectrum processing}

PLSPlus/IQ in GRAMS/AI 8.0 (Thermo Electron Corp.), Delphi 2005 (Borland Software Corp.) and Excel 2000 (Microsoft Corp.) were used to acquire, exchange and analyze the spectra. Most of the pre-processing, pre-treatment and calibration methods used in this study were programmed in Delphi 2005 by the research team and validated by comparing the results with GRAMS. Since the pre-processing tools and chemometric methods programmed in Delphi 2005 can be easily modified, the development of these routines was fundamental to allow inclusion of additional pre-treatments or calibration models, and to change the order of application.

Due to the fact that water exhibits high absorption in the 1400-1450 nm and 1900-1960 nm ranges, each spectrum was collected over the 1100-2200 nm region with a $4.5 \mathrm{~nm}$ sampling interval and a resolution of about $15 \mathrm{~nm}$ bandwidth. After averaging over 295 spectra, the negative logarithm of the relative reflectance $(R)$ of each spectrum was calculated:

$$
A=-\log (1 / R) A
$$

where $\mathrm{A}$ is the absorbance and $\mathrm{R}$ is the ratio of each spectrum to the reference spectrum of a white ceramic. In order to be able to compute first and second derivatives, every absorbance spectrum was smoothed by using a 4-point binomial filter. Binomial filters, based on an approximation to the Gaussian filters, are simple structures for accurate filtering and efficient hardware implementation. The structure of binomial filters and the mode of obtaining the coefficients were described in a previous study by Aubury and Luk (1995). Derivatives of smoothed spectra in this investigation did not show noise-related peaks that contained irrelevant information. Therefore, smoothing was a necessary pre- 
processing in this study. SNV (Standard Normal Variate) was applied after smoothing and before applying several combinations of different pre-treatment methods (mean centering, first derivative, second derivative and variable selection). First and second derivatives were computed by means of Savitzky-Golay's method with a 2nd-order polynomial and a 5-point window. Owing to the binomial smoothing performed, a 5-point window was sufficient to attain a suitable derivative. The variable selection was carried out by analyzing the calibration and validation performance of two spectral ranges: $1100-2200 \mathrm{~nm}$ and $1800-2000 \mathrm{~nm}$.

After applying the pre-processing and pre-treatment tools, a mathematical model was needed to correlate NIR instrument output (spectra) and reference measurements (obtained by KF). In this study, principal component regression (PCR) and partial least squares regression (PLSR) were used to construct the optimum mathematical model because both algorithms have been widely employed and thoroughly analyzed, and have shown powerful properties in multivariate analysis (Martens, Martens, 2001; Beebe, Kowalski, 1987; Wold et al., 2001; Beebe et al.,1998; Kramer, 1998).

\section{RESULTS AND DISCUSSION}

\section{Karl Fischer}

The overall range obtained by KF titration was from 0 to $8.2 \%(\mathrm{w} / \mathrm{w})$. Validation samples were selected in such a way that moisture content lay at points in between calibration points, in order to evaluate the interpolating ability of the calibration model.

\section{Direct reflections}

As mentioned in the NIR Measurement Section, the probe was inclined at a suitable angle in order to avoid direct reflections from the bottom of the vial. Figure 2 shows that the direct reflection strongly decreases when the angle approximates to the numerical aperture of the fiber (a simple demonstration of the connection between these two parameters can be readily found). Based on the numerical aperture of the fiber employed in this study, an angle of approximately 15 degrees, which corresponds to curve $a$ in Figure 2, was the optimum angle found, i.e. the angle that minimizes direct reflections without causing a great loss of diffuse reflectance. The spectra shown in Figure 2 were acquired by using an empty vial over a dark substrate and modifying the angle between the probe and the bottom of the vial.

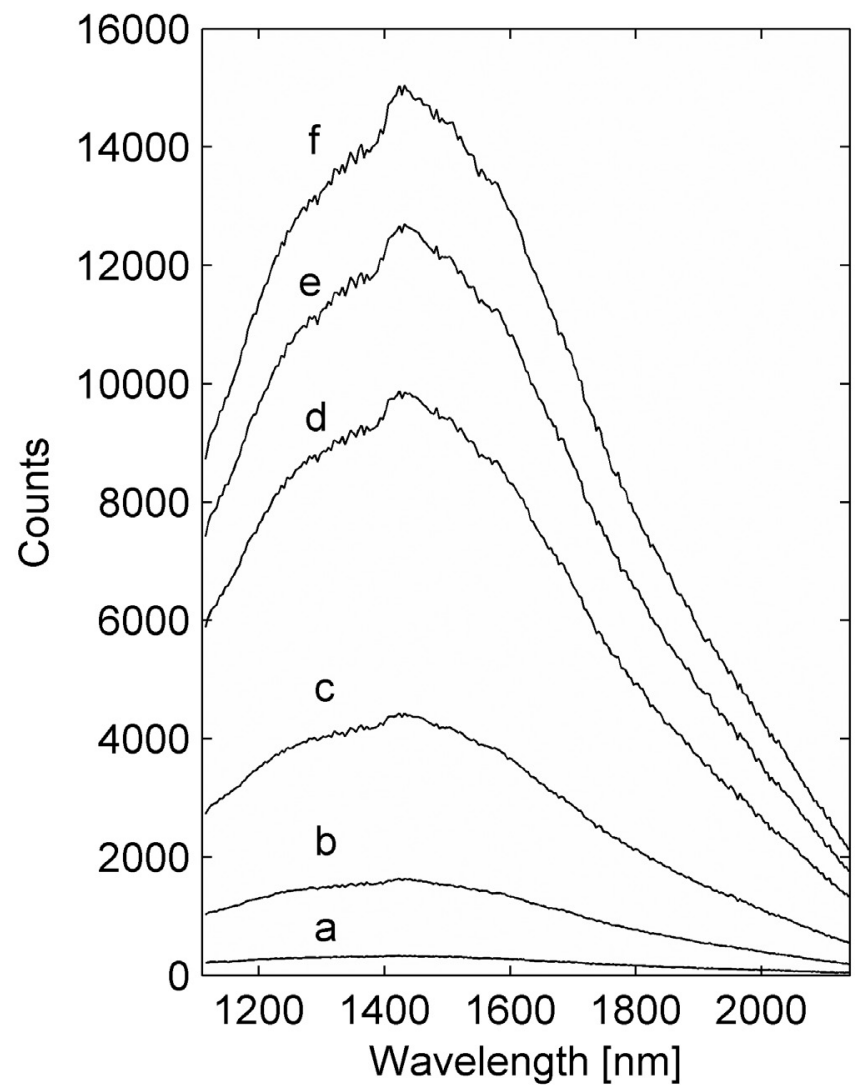

FIGURE 2 - Near-infrared spectra obtained from the bottom of an empty glass vial, set up at different angles with respect to the probe: curve (a) corresponds to an angle of ca. 15 degrees, curve (f) corresponds to an angle of ca. 0 degrees, and curves (b-e) correspond to intermediate angles.

\section{Spectrum analysis}

Every freeze-dried cake that exhibited volume reduction related to the process of sample generation was gently shaken as described in the Samples Section. Significant changes have been observed in the spectra measured from these shaken vials, due to changes in path length, bulk density and particle size. Therefore, further analysis was carried out to determine the best pre-treatment method in order to avoid these changes. Based on the additional analysis, SNV was found to be the best pre-treatment and was employed in this study as a critical and mandatory method. Figure 3 shows the absorption spectra measured before and after shaking the same vial, which exhibited volume reduction in its freeze-dried cake, and depicts the result obtained from the application of SNV to those spectra. Unlike the spectra " $a$ " and " $b$ " in Figure 3, spectra "c" and "d" clearly show similar spectral features, e.g. the differences in amplitude and baseline have almost disappeared. 


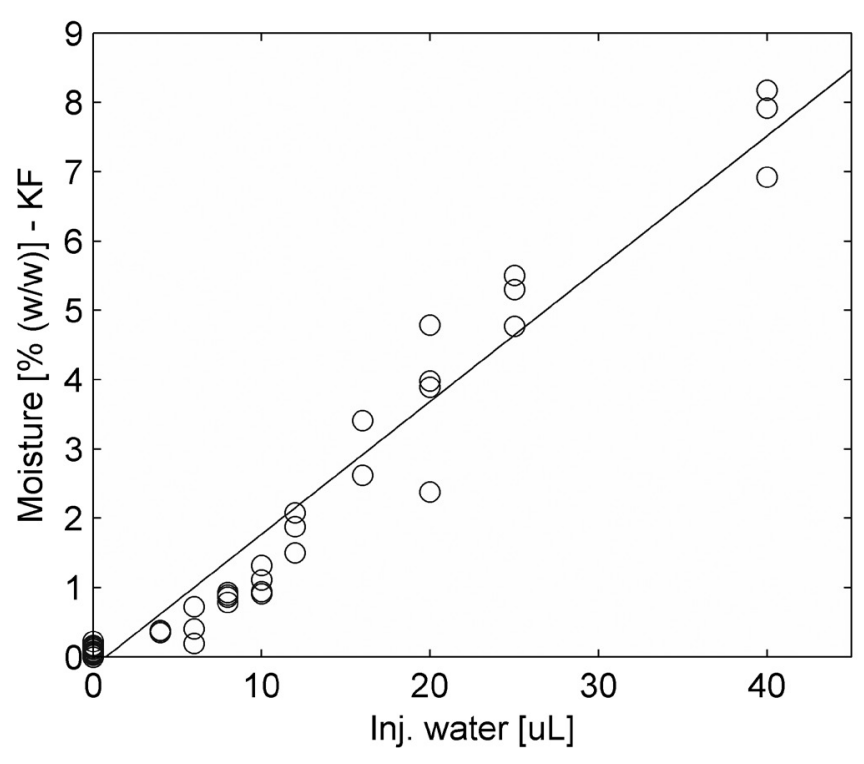

FIGURE 3 - Near-infrared spectrum of a representative vial with 4-points binomial filter (a) after and (b) before being gently shaken, and with 4-points binomial filter and SNV (c) after and (d) before being gently shaken.

\section{Model development}

Model development is a time-consuming task because several combinations of pre-processing and pretreatment algorithms, regression methods and variable ranges have to be evaluated to generate a robust and accurate calibration. In addition, many other properties of the model must be considered, e.g. linearity, repeatability etc. To assess calibration and prediction performance, the corresponding root mean square error of calibration (RMSEC) (Beebe et al.,1998; Kramer, 1998), root mean square error of prediction (RMSEP) (Beebe et al.,1998; Kramer, 1998; Rodrigues et al., 2005) and relative standard error of prediction (RSEP) (Blanco et al.,1997; Brülls et al., 2007; Rodrigues et al., 2005) for these combinations were calculated and listed in Table I, wherein

$$
\begin{gathered}
R M S E C=\left[\sum_{i=1}^{n_{c}}\left(y_{i}^{c}-\hat{y}_{i}^{c}\right)^{2} /\left(n_{c}-d-1\right)\right]^{1 / 2} \\
\operatorname{RMSEP}=\left[\sum_{i=1}^{n_{p}}\left(y_{i}^{p}-\hat{y}_{i}^{p}\right)^{2} / n_{p}\right]^{1 / 2} \\
\operatorname{RSEP}(\%)=\left[\sum_{i=1}^{n_{p}}\left(y_{i}^{p}-\hat{y}_{i}^{p}\right)^{2} / \sum_{i=1}^{n_{p}}\left(y_{i}^{p}\right)^{2}\right]^{1 / 2} \times 100
\end{gathered}
$$

In equations (2)-(4), $n_{c}$ and $n_{p}$ indicate the number of samples included in the calibration and prediction set, respectively, $d$ is the number of factors, $y_{i}^{c}$ and $y_{i}^{p}$ are the moisture content for the $i$ th sample in the calibration and prediction set, respectively, and $\hat{y}_{i}^{c}$ and $\hat{y}_{i}^{p}$ are the fitted moisture content for the $i$ th sample in the calibration and prediction set, respectively.

Likewise, the number of factors, linearity and repeatability for each combination are shown in Table I. Linearity was evaluated by considering the slope, intercept and $R^{2}$ of predicted values plotted against the reference method values. The optimum number of factors for both PCR and PLS-1 was determined by correcting the number of factors informed by PLSPlus/IQ. As stated by Zhou et al. (Zhou et al., 1998), the number of factors based on the F-test of the prediction residual error sum of squares (PRESS) is not necessarily equal to the number of factors which provides the lowest RMSEP, but in this study it was deemed to be a convenient starting point. Therefore, the numbers of factors immediately above and below the number of factors informed by PLSPlus/IQ were also analyzed.

Finally, 50 consecutive determinations of the same sample (ca. $4.2 \%(\mathrm{w} / \mathrm{w}))$ were carried out to assess repeatability by means of the relative standard deviation $(R S D)$ obtained under repeatability conditions.

\section{Model assessment}

After acquiring the near infrared spectra, different chemometric methods (e.g. variable selection, smoothing, mean centering) were applied and the results are shown in Table I. As seen in this table, two spectral ranges (1100-2200 nm; $1800-2000 \mathrm{~nm})$ and four different numbers of factors for both PCR and PLS-1, were analyzed. The numbers of factors marked with an asterisk are those recommended by GRAMS, and the numbers of factors immediately above and below those were also analyzed, as mentioned in the Model Development Section. An additional number of factors were obtained by using the convention of the elbow in the PRESS graph. Models generated in the 1100$2200 \mathrm{~nm}$ region produced, in most of the combinations, lower RMSEC values for the same number of factors than the models generated in the $1800-2000 \mathrm{~nm}$ region. In addition, Table I shows that PLS needed a lower number of factors to reach a similar RMSEC in comparison to PCR, and the reduction in the spectral range and the second derivative had a remarkable and undesirable effect on repeatability. Based on its robustness (usually fewer factors included imply more robust models), RMSEC, RMSEP, and repeatability, the model generated by using SNV and PLS-1 (3 factors) was selected. It is worth noting that, in a similar combination of ranges, second derivative tended to increase the standard deviation of the replicates. This effect can be explained from the well-known property of derivatives of increasing differences between approximated and actual values. Thus, it is advisable to avoid derivatives whenever the enhancements in robustness or linearity do not compensate the loss 
TABLE I - Results obtained after application of different combinations of pre-treatments, spectral ranges and multivariate methods in the full moisture content range. Asterisks indicate the number of factors recommended by PLSPlus/IQ (Sm: smoothing; MC: mean centering; SNV: Standard Normal Variate; FD: first derivative; SD: second derivative; Repeat.: repeatability)

\begin{tabular}{|c|c|c|c|c|c|c|c|c|c|c|}
\hline \multirow{2}{*}{ Model } & \multirow{2}{*}{$\begin{array}{c}\text { Range } \\
\text { (nm) }\end{array}$} & \multirow{2}{*}{ Pre-treatment } & \multirow{2}{*}{ Factors } & \multirow{2}{*}{ RMSEC } & \multirow{2}{*}{ RMSEP } & \multirow{2}{*}{$\begin{array}{c}\text { RSEP } \\
(\%)\end{array}$} & \multicolumn{3}{|c|}{ Pred. Linearity } & \multirow{2}{*}{ Repeat. } \\
\hline & & & & & & & Slope & Intercept & $\mathrm{R}^{2}$ & \\
\hline \multirow{4}{*}{ PCR } & \multirow{4}{*}{$1100-2200$} & \multirow{4}{*}{$\mathrm{Sm}+\mathrm{SNV}+\mathrm{MC}$} & 4 & 0.137 & 0.262 & 9.19 & 0.940 & 0.0298 & 0.991 & $0.63 \%$ \\
\hline & & & 19 & 0.119 & 0.269 & 9.09 & 0.932 & 0.0353 & 0.992 & $0.75 \%$ \\
\hline & & & $20 *$ & 0.116 & 0.266 & 8.95 & 0.935 & 0.0335 & 0.992 & $0.64 \%$ \\
\hline & & & 21 & 0.117 & 0.267 & 8.96 & 0.935 & 0.0332 & 0.992 & $0.66 \%$ \\
\hline \multirow{4}{*}{ PCR } & \multirow{4}{*}{$1800-2000$} & \multirow{4}{*}{$\mathrm{Sm}+\mathrm{SNV}+\mathrm{MC}$} & 4 & 0.114 & 0.283 & 9.91 & 0.924 & 0.0626 & 0.991 & $0.74 \%$ \\
\hline & & & 10 & 0.168 & 0.306 & 10.6 & 0.916 & 0.056 & 0.991 & $1.29 \%$ \\
\hline & & & $11^{*}$ & 0.154 & 0.304 & 10.5 & 0.913 & 0.0743 & 0.991 & $1.20 \%$ \\
\hline & & & 12 & 0.155 & 0.301 & 10.4 & 0.915 & 0.0704 & 0.991 & $1.20 \%$ \\
\hline \multirow{4}{*}{ PLS } & \multirow{4}{*}{$1100-2200$} & \multirow{4}{*}{$\mathrm{Sm}+\mathrm{SNV}+\mathrm{MC}$} & 3 & 0.139 & 0.248 & 8.80 & 0.945 & 0.0218 & 0.992 & $0.61 \%$ \\
\hline & & & 10 & 0.111 & 0.266 & 9.27 & 0.937 & 0.0075 & 0.992 & $0.64 \%$ \\
\hline & & & $11^{*}$ & 0.106 & 0.265 & 9.25 & 0.936 & 0.0178 & 0.992 & $0.63 \%$ \\
\hline & & & 12 & 0.099 & 0.261 & 9.10 & 0.943 & 0.0037 & 0.992 & $0.72 \%$ \\
\hline \multirow{4}{*}{ PLS } & & & 3 & 0.232 & 0.315 & 11.01 & 0.912 & 0.0629 & 0.990 & $0.67 \%$ \\
\hline & $1800-2000$ & $\mathrm{Sm}+\mathrm{SN}$ & 6 & 0.159 & 0.277 & 9.70 & 0.926 & 0.0431 & 0.992 & $1.10 \%$ \\
\hline & $1800-2000$ & $\mathrm{Sm}^{+}$ & $7 *$ & 0.154 & 0.310 & 10.78 & 0.918 & 0.0428 & 0.990 & $1.17 \%$ \\
\hline & & & 8 & 0.145 & 0.304 & 10.57 & 0.914 & 0.0709 & 0.990 & $1.43 \%$ \\
\hline & & & 4 & 0.219 & 0.264 & 9.28 & 0.936 & 0.0672 & 0.991 & $0.68 \%$ \\
\hline & & & 9 & 0.129 & 0.273 & 9.33 & 0.925 & 0.0721 & 0.992 & $0.70 \%$ \\
\hline PCR & $1100-2200$ & $\mathrm{Sm}+\mathrm{SNV}+\mathrm{FD}+\mathrm{MC}$ & $10 *$ & 0.127 & 0.263 & 8.98 & 0.929 & 0.0666 & 0.993 & $0.68 \%$ \\
\hline & & & 11 & 0.127 & 0.266 & 9.07 & 0.929 & 0.0661 & 0.993 & $0.68 \%$ \\
\hline & & & 3 & 0.224 & 0.277 & 9.67 & 0.930 & 0.0829 & 0.990 & $0.89 \%$ \\
\hline & & & 7 & 0.216 & 0.267 & 9.39 & 0.928 & 0.0763 & 0.992 & $0.97 \%$ \\
\hline PCR & $1800-2000$ & $\mathrm{Sm}+\mathrm{SNV}$ & $8 *$ & 0.152 & 0.306 & 10.61 & 0.916 & 0.063 & 0.990 & $1.01 \%$ \\
\hline & & & 9 & 0.152 & 0.303 & 10.50 & 0.917 & 0.0622 & 0.990 & $1.02 \%$ \\
\hline & & & 3 & 0.201 & 0.254 & 8.86 & 0.938 & 0.0671 & 0.992 & $0.68 \%$ \\
\hline & & & 4 & 0.130 & 0.272 & 9.47 & 0.929 & 0.0513 & 0.991 & $0.65 \%$ \\
\hline PLS & $1100-2200$ & $\mathrm{Sm}+\mathrm{SNV}+\mathrm{FD}+\mathrm{MC}$ & $5^{*}$ & 0.118 & 0.274 & 9.56 & 0.929 & 0.045 & 0.991 & $0.67 \%$ \\
\hline & & & 6 & 0.115 & 0.270 & 9.24 & 0.934 & 0.0297 & 0.992 & $0.64 \%$ \\
\hline & & & 2 & 0.216 & 0.276 & 9.62 & 0.930 & 0.0783 & 0.990 & $0.89 \%$ \\
\hline & & & 3 & 0.170 & 0.276 & 9.60 & 0.919 & 0.083 & 0.992 & $0.86 \%$ \\
\hline PLS & $1800-2000$ & $\mathrm{Sm}+\mathrm{SNV}+\mathrm{FD}+\mathrm{MC}$ & $4^{*}$ & 0.148 & 0.299 & 10.34 & 0.914 & 0.071 & 0.991 & $1.01 \%$ \\
\hline & & & 5 & 0.144 & 0.306 & 10.53 & 0.913 & 0.080 & 0.990 & $1.12 \%$ \\
\hline & & & 4 & 0.216 & 0.260 & 8.95 & 0.932 & 0.099 & 0.992 & $0.70 \%$ \\
\hline & & & 14 & 0.092 & 0.301 & 10.27 & 0.942 & 0.0212 & 0.987 & $1.83 \%$ \\
\hline PCR & $1100-2200$ & $\mathrm{Sm}+\mathrm{SNV}$ & 15 & 0.085 & 0.301 & 10.27 & 0.944 & 0.0214 & 0.987 & $1.80 \%$ \\
\hline & & & 16 & 0.079 & 0.300 & 10.16 & 0.947 & 0.0063 & 0.988 & $1.67 \%$ \\
\hline & & & 5 & 0.193 & 0.253 & 8.73 & 0.945 & 0.0663 & 0.991 & $1.84 \%$ \\
\hline & & & 7 & 0.166 & 0.283 & 9.82 & 0.941 & 0.0593 & 0.988 & $2.14 \%$ \\
\hline PCR & $1800-2000$ & $\mathrm{Sm}+\mathrm{SNV}+\mathrm{SD}+\mathrm{MC}$ & 8 & 0.161 & 0.285 & 9.87 & 0.941 & 0.0562 & 0.988 & $2.20 \%$ \\
\hline & & & 9 & 0.159 & 0.288 & 9.92 & 0.939 & 0.0635 & 0.988 & $2.13 \%$ \\
\hline & & & 4 & 0.216 & 0.260 & 8.95 & 0.932 & 0.099 & 0.992 & $0.70 \%$ \\
\hline & & & 14 & 0.092 & 0.301 & 10.27 & 0.942 & 0.0212 & 0.987 & $1.83 \%$ \\
\hline PLS & $1100-2200$ & $\mathrm{Sm}+\mathrm{SNV}+\mathrm{SD}+\mathrm{MC}$ & 15 & 0.085 & 0.301 & 10.27 & 0.944 & 0.0214 & 0.987 & $1.80 \%$ \\
\hline & & & 16 & 0.079 & 0.300 & 10.16 & 0.947 & 0.0063 & 0.988 & $1.67 \%$ \\
\hline & & & 4 & 0.213 & 0.255 & 8.78 & 0.947 & 0.0612 & 0.991 & $1.73 \%$ \\
\hline & & & 7 & 0.166 & 0.283 & 9.82 & 0.941 & 0.0593 & 0.988 & $2.14 \%$ \\
\hline PLS & $1800-2000$ & $\mathrm{Sm}+\mathrm{SNV}+\mathrm{SD}+\mathrm{MC}$ & 8 & 0.161 & 0.285 & 9.87 & 0.941 & 0.0562 & 0.988 & $2.20 \%$ \\
\hline & & & 9 & 0.159 & 0.288 & 9.92 & 0.939 & 0.0635 & 0.988 & $2.13 \%$ \\
\hline
\end{tabular}


TABLE II - Results obtained after application of different combinations of pre-treatments, spectral ranges and multivariate methods in the low moisture content range $(0-1 \%(\mathrm{w} / \mathrm{w}))$

\begin{tabular}{|c|c|c|c|c|c|c|c|c|c|}
\hline \multirow[t]{2}{*}{ Model } & \multirow{2}{*}{$\begin{array}{c}\text { Range } \\
(\mathrm{nm})\end{array}$} & \multirow[t]{2}{*}{ Pre-treatment } & \multirow[t]{2}{*}{ Factors } & \multirow[t]{2}{*}{ RMSEC } & \multirow[t]{2}{*}{ RMSEP } & \multirow{2}{*}{$\begin{array}{c}\text { RSEP } \\
(\%)\end{array}$} & \multicolumn{2}{|c|}{ Pred. Linearity } & \multirow[t]{2}{*}{$\mathrm{R}^{2}$} \\
\hline & & & & & & & Slope & Intercept & \\
\hline$\overline{\mathrm{PCR}}$ & $1100-2200$ & $\mathrm{Sm}+\mathrm{SNV}+\mathrm{MC}$ & 5 & 0.076 & 0.078 & 23.51 & 0.904 & -0.0002 & 0.924 \\
\hline PCR & $1800-2000$ & $\mathrm{Sm}+\mathrm{SNV}+\mathrm{MC}$ & 5 & 0.084 & 0.058 & 15.83 & 0.944 & 0.0158 & 0.963 \\
\hline PLS & $1800-2000$ & $\mathrm{Sm}+\mathrm{SNV}+\mathrm{MC}$ & 4 & 0.080 & 0.056 & 15.25 & 0.926 & 0.0152 & 0.967 \\
\hline PCR & $1100-2200$ & $\mathrm{Sm}+\mathrm{SNV}+\mathrm{MC}+\mathrm{FD}$ & 5 & 0.086 & 0.062 & 16.94 & 0.942 & 0.0241 & 0.959 \\
\hline PLS & $1800-2000$ & $\mathrm{Sm}+\mathrm{SNV}+\mathrm{MC}+\mathrm{FD}$ & 2 & 0.081 & 0.058 & 15.90 & 0.962 & 0.0159 & 0.963 \\
\hline PCR & $1100-2200$ & $\mathrm{Sm}+\mathrm{SNV}+\mathrm{MC}+\mathrm{SD}$ & 12 & 0.098 & 0.079 & 21.37 & 0.959 & 0.0343 & 0.943 \\
\hline PLS & $1100-2200$ & $\mathrm{Sm}+\mathrm{SNV}+\mathrm{MC}+\mathrm{SD}$ & 7 & 0.068 & 0.064 & 17.60 & 0.933 & 0.011 & 0.954 \\
\hline PCR & $1800-2000$ & $\mathrm{Sm}+\mathrm{SNV}+\mathrm{MC}+\mathrm{SD}$ & 6 & 0.124 & 0.093 & 25.47 & 0.837 & 0.0149 & 0.913 \\
\hline PLS & $1800-2000$ & $\mathrm{Sm}+\mathrm{SNV}+\mathrm{MC}+\mathrm{SD}$ & 9 & 0.082 & 0.057 & 15.73 & 0.949 & 0.0093 & 0.963 \\
\hline
\end{tabular}

of repeatability or limit of quantitation (LOQ). In order to improve the RMSEP of samples with low moisture content, additional calibrations in the range $0-1 \%(\mathrm{w} / \mathrm{w})$ were performed (the results are presented in Table II). The restricted calibration obtained with only 3 PLS-1 factors from spectra pre-processed by SNV and first derivative was selected $(\mathrm{RMSEP}=0.055 \%(\mathrm{w} / \mathrm{w}))$. Finally, a new model was generated from a combination of the original and restricted calibrations, leading to: $\mathrm{R}-\mathrm{SEC}=0.117 \%(\mathrm{w} / \mathrm{w})$; calibration slope $=0.992 ;$ calibration intercept $=0.0174 ; R_{C a l}^{2}=0.996$; $\mathrm{RMSEP}=0.233 \%(\mathrm{w} / \mathrm{w}) ; \mathrm{RSEP}=8.21 \%(\mathrm{w} / \mathrm{w})$; prediction

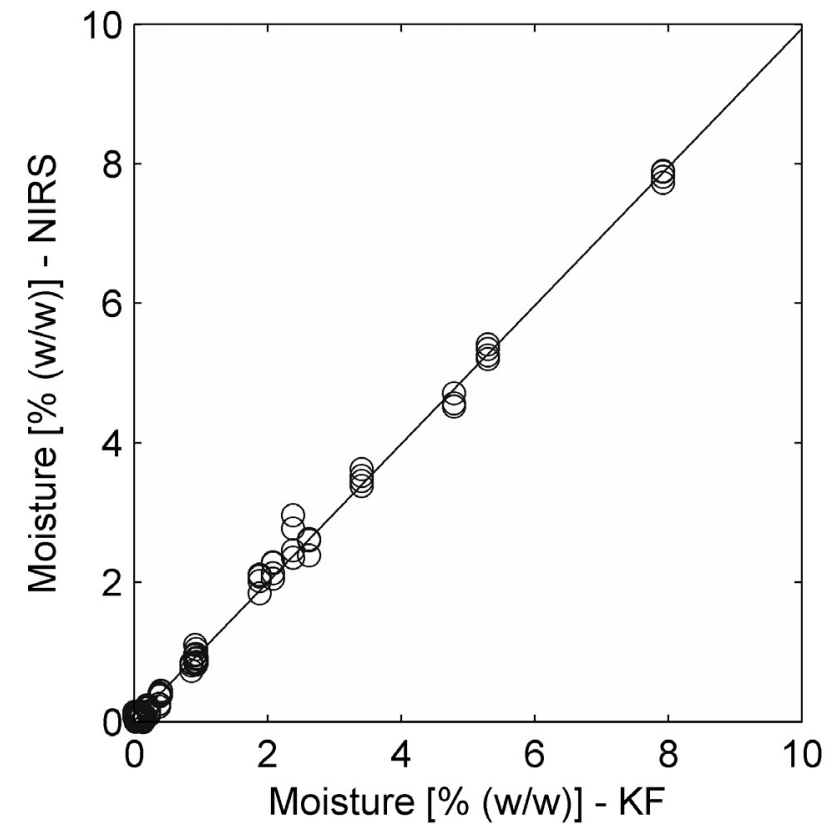

FIGURE 4A - Plot of predicted (NIRS) versus actual (KF) moisture content for calibration samples. The solid line represents a linear regression data fit. slope $=0.944 ;$ prediction intercept $=0.0147 ; R_{\text {Pred }}^{2}=0.994$. The limit of detection (LOD) and LOQ were estimated by calculating the standard deviation (SD) of samples from the calibration and validation sets with moisture content close to the LOD and LOQ (range was selected iteratively) and multiplying each SD by 3 and 10, respectively (Patel et al., 2001; Seyer et al., 2000). This estimation provides an approximate LOD value of $0.22 \%(\mathrm{w} / \mathrm{w})$ and LOQ value of $0.73 \%(\mathrm{w} / \mathrm{w})$. Plots $\mathrm{a}$ and $\mathrm{b}$ in Figure 4 show the predicted (NIRS method - combined model) versus measured (KF method) values for the calibration and prediction sets of

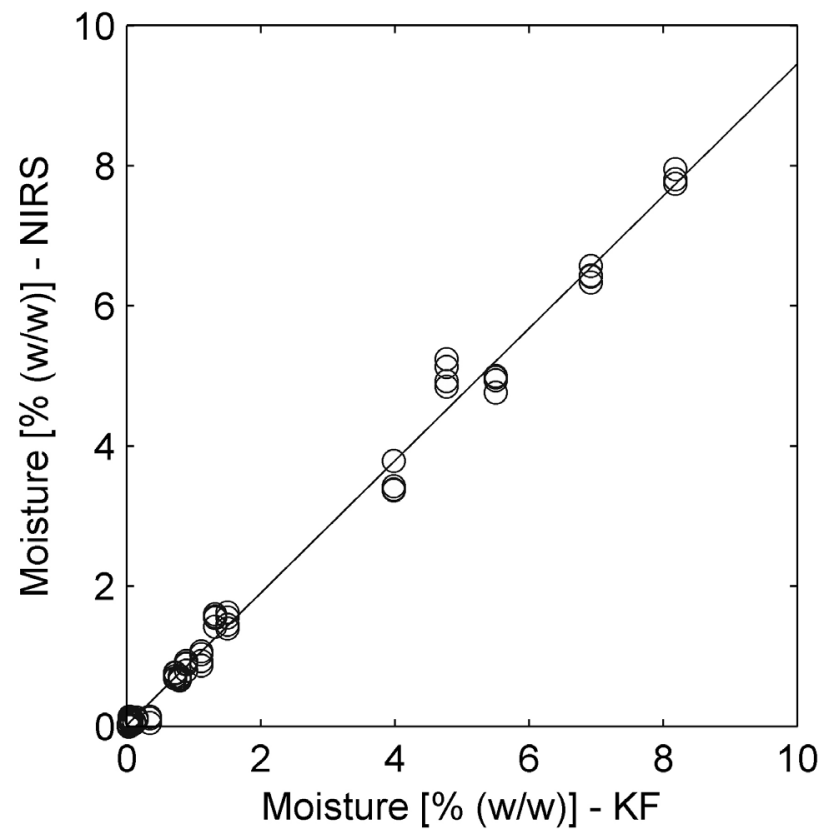

FIGURE 4B - Plot of predicted (NIRS) versus actual (KF) moisture content for validation samples. The solid line represents a linear regression data fit. 
samples, respectively. In these plots, the spectra acquired at different temperatures are included and, given that it is not possible to detect any deviation due to this variable, it is reasonable to assume that the model is robust in the temperature range considered.

\section{CONCLUSIONS}

The ultimate aim of this research work was to prove that a robust and fast micro-spectrometer could be used to measure the total amount of water in lyophilized mannitol through intact glass, and to determine the best pre-processing, pre-treatment, and multivariate method related to this measurement. The major challenges in this study were the inferior resolution of micro-spectrometers, the low signal intensity of mannitol with very low water content, and the problems associated with measurements through the glass vial (e.g. reflections, variations in the glass). The results of this study demonstrated the potential of microspectrometers for performing measurements of moisture content of products inside sealed glass vials through a reflectance probe. Therefore, it is reasonable to conclude that, after minor adaptations, micro-spectrometers similar to that used in this research could be readily introduced in a production environment within the PAT framework (FDA, 2004), leading subsequently to a better understanding of the process from the data collected in real time.

\section{ACKNOWLEDGEMENTS}

The authors would like to thank the Fontar program (ANR 600 NA 205/06) and Buenos Aires Innova program $\left(\mathrm{N}^{\circ} 60565 / 2006\right)$ for funding this research, Laboratorios IMA for providing the lyophilized samples and performing several Karl Fischer titrations, and HITEC for authorizing the publication of this work. Furthermore, the authors gratefully acknowledge Dr. E. O. Timmermann (ANCBA) and R. J. Diaz (HITEC) for valuable discussions.

\section{REFERENCES}

AUBURY, M.; LUK, W. Binomial filters. J. VLSI Signal Process., v.1, p.1-8, 1995.

BEEBE, K.R.; PELL, R.J.; SEASHOLTZ, M.B. Chemometrics: A practical guide. New York: John Wiley \& Sons, 1998. $348 \mathrm{p}$.

BEEBE, K.R; KOWALSKI, B.R. An introduction to multivariate calibration and analysis. Anal. Chem., v.59, n.17, p.1007A1017A, 1987.
BERNTSSON, O.; DANIELSSON, L-G.; FOLESTAD, S. Estimation of effective sample size when analysing powders with diffuse reflectance near-infrared spectrometry. Anal. Chim. Acta, v.364, n.1-3, p.243-251, 1998.

BLANCO, M.; COELLO, J.; ITURRIAGA, H.; MASPOCH, S.; ROVIRA, E. Determination of water in ferrous lactate by near infrared reflectance spectroscopy with a fibre-optic probe. J. Pharm. Biomed. Anal., v.16, n.2, p.255-262, 1997.

BOTEZ, C.E.; STEPHENS, P.W.; NUNES, C.; SURYANARAYANAN, R. Crystal structure of anhydrous d-D-mannitol. Powder Diffr., v.18, n.3, p.214-218, 2003.

BRÜLLS, M.; FOLESTAD, S.; SPARÉN, A.; RASMUSON, A.; SALOMONSSON. J. Applying spectral peak area analysis in near-infrared spectroscopy moisture assays. J. Pharm. Biomed. Anal., v.44, n.1, p.127-136, 2007.

BÜNING-PFAUE, H. Analysis of water in food by near infrared spectroscopy. Food. Chem., v.82, n.1, p.107-115, 2003.

CANNON, A.J.; TRAPPLER, E.H. The influence of lyophilization on the polymorphic behavior of mannitol. PDA J. Pharm. Sci. Tech., v.54, n.1, p.13-22, 2000.

CAO, W.; MAO, C.; CHEN, W.; LIN, H.; KRISHNAN, S., CAUCHON, N. Differentiation and quantitative determination of surface and hydrate water in lyophilized mannitol using NIR spectroscopy. J. Pharm. Sci., v.95, n.9, p.2077-2086, 2006.

DERBYSHIRE, H.M.; FELDMAN, Y.; BLAND, C.R.; BROADHEAD, J.; SMITH, G. A study of the molecular properties of water in hydrated mannitol. J. Pharm. Sci., v.91, n.4, p.1080-1088, 2002.

DERKSEN, M.W.J.; VAN DE OETELAAR, P.J.M.; MARIS, F.A. The use of near-infrared spectroscopy in the efficient prediction of a specification for the residual moisture content of a freeze-dried product. J. Pharm. Biomed. Anal., v.17, n.3, p.473-480, 1998.

FOOD AND DRUG ADMINISTRATION. FDA. Guidance for Industry PAT - A Framework for Innovative Pharmaceutical Development, Manufacturing, and Quality Assurance. Available at: <http://www.fda.gov/downloads/Drugs / GuidanceComplianceRegulatoryInformation/Guidances/ UCM070305.pdf>. Accessed on: 14th may 2010. 
KAMAT, M.S.; LODDER, R.A.; DELUCA, P.P. Near-infrared spectroscopic determination of residual moisture in lyophilized sucrose through intact glass vials. Pharm. Res., v.6, n.11, p.961-965, 1989.

KRAMER, R. Chemometric techniques for quantitative analysis. New York: Marcel Dekker, Inc., 1998. 203 p.

MARTENS, H.; MARTENS, M. Multivariate analysis of quality: an introduction. Chichester: John Wiley \& Sons, 2001. $445 \mathrm{p}$.

PATEL, A.D.; LUNER, P.E.; KEMPER, M.S. Low-level determination of polymorph composition in physical mixtures by near-infrared reflectance spectroscopy. $J$. Pharm. Sci., v.90, n.3, p.360-370, 2001.

RODRIGUES, L.O.; MARQUES, J.L.; CARDOSO J.P.; MENEZES J.C. From lab to plant: a scale-independent NIR calibration to monitor an ionic exchange column. Chemom. Intell. Lab. Syst., v.75, n.1, p.101-108, 2005.

ROGGO, Y.; CHALUS, P.; MAURER, L.; LEMA-MARTINEZ, C.; EDMOND, A.; JENT, N. A review of near infrared spectroscopy and chemometrics in pharmaceutical technologies. J. Pharm. Biomed. Anal., v.44, n.3, p.683700, 2007.

SEYER, J.J.; LUNER, P.E.; KEMPER, M.S. Application of diffuse reflectance near-infrared spectroscopy for determination of crystallinity. J. Pharm. Sci., v.89, n.10, p.1305-1316, 2000.

SHENK, J.S.; WORKMAN, JR., J.J.; WESTERHAUS, M.O. Application of NIR spectroscopy to agricultural products. In: BURNS, D.A.; CIURCZAK, E.W. (Eds.). Handbook of near-infrared analysis. 3.ed. Boca Raton: Taylor \& Francis Group, 2008. p.347-386.
STOKVOLD, A.; DYRSTAD, K.; LIBNAU, F.O. Sensitive NIRS measurement of increased moisture in stored hygroscopic freeze dried product. J. Pharm. Biomed. Anal., v.28, n.5, p.867-873, 2002.

WOLD, S.; TRYGG, J.; BERGLUND, A.; ANTTI, H. Some recent developments in PLS modeling. Chemom. Intell. Lab. Syst., v.58, n.2, p.131-150, 2001.

XIE, Y.; CAO, W.; KRISHNAN, S.; LIN, H.; CAUCHON, N. Characterization of mannitol polymorphic forms in lyophilized protein formulations using a multivariate curve resolution (MCR)-based Raman spectroscopic method. Pharm. Res., v.25, n.10, p.2292-2301, 2008.

ZHENG Y.; LAI X.; BRUUN S.W.; IPSEN H.; LARSEN J.N.; LØWENSTEIN H.; SØNDERGAARD I.; JACOBSEN S. Determination of moisture content of lyophilized allergen vaccines by NIR spectroscopy. J. Pharm. Biomed. Anal., v.46, n.3, p.592-596, 2008.

ZHOU, X.; HINES, P.; BORER, M.W. Moisture determination in hygroscopic drug substances by near infrared spectroscopy. J. Pharm. Biomed. Anal., v.17, n.2, p.219-225, 1998.

ZHOU, G.X.; GE, Z.; DORWART, J.; IZZO, B.; KUKURA, J.; BICKER, G.; WYVRATT, J. Determination and differentiation of surface and bound water in drug substances by near infrared spectroscopy. J. Pharm. Sci., v.92, n.5, p.1058-1065, 2003.

Received for publication on $20^{\text {th }}$ May 2010. Accepted for publication on $25^{\text {th }}$ October 2010. 
